\title{
Vài dòng cảm xúc trước thềm xuân mới Tân Sửu 2021
}

\author{
$\mathrm{VQH}$
}

Hà Nội, ngày 16 tháng 1 năm 2021

Đất nước vừa qua một năm khó khăn với đại dịch COVID-19. Cả thế giới vẫn đang oằn mình chống đỡ; góc này, nơi kia vẫn là những tin tức về số ca nhiễm mới, chủng nguy hiểm hơn, số người tử vong, và cả cảnh báo diện rộng.

Nhưng mùa xuân vẫn về theo quy luật tự nhiên. Phố phường Hà Nội sẽ vẫn tiếp tục náo nhiệt, và vẫn có hy vọng lại có những người đi xin chữ Ông Đồ. Trong thi ca Việt Nam, bài thơ Ông Đồ của Vũ Đình Liên có một vị trí trang trọng, và không thể quên lãng. Ai quên thì Tết đến cũng sẽ được nhắc nhớ.

Mười năm trước, Thu Trang dịch bài thơ Ông Đồ sang tiếng Anh. Bản gốc được đưa lên trang web Giúp Con Học, nay không còn chạy nữa. Nhưng bản dịch đó cũng đã được lần lượt nhiều trang web về giáo dục phổ thông, giảng dạy tiếng Anh đăng tải lại [1]. Đến năm 2018, dịch giả Phạm Trọng Lệ trong bài [2] đã đích thân mình tuyển lựa các bản dịch bài Ông Đồ tiêu biểu và hay nhất để giới thiệu về ý nghĩa Tết ở Việt Nam. Bản dịch của Thu Trang được chọn lựa đưa vào bài, và cũng là bản dịch mới nhất trên văn đàn thi ca Việt Nam.

Thoáng cái, vậy mà cũng đã hơn 10 năm kể từ ngày bản dịch ấy hoàn thành và đưa lên mạng cho mọi người cùng đọc.

... 10 năm ấy, hạt mít gieo trước thềm cửa, nay đã cao gần 8 mét, vài đợt trổ hoa.

... 10 năm ấy, từ khi chỉ đờ đẫn người ngồi nghe tin giải thưởng Fields danh giá trao tặng cho nhà toán học lỗi lạc Ngô Bảo Châu, thế rồi cũng tới lúc đã trải qua 4 năm cùng nhau chung sức xây dựng dự án [3].

... 10 năm ấy, một thời gian dài đằng đẵng gồm cả những khúc chìm mình trong khó khăn để gây dựng công việc với đội ngũ trẻ, tạo dựng truyền thống nghiên cứu khoa học tại trường ĐH Thành Tây (lúc không có tên tuổi) cho tới khi có một trường ĐH Phenikaa vụt sáng như ngôi sao gần đây [4].

... 10 năm ấy, trải biết bao khó khăn để hoàn thành công việc, trong ấy có những thứ xưa kia tưởng là không thể như xuất bản trên Nature, mà chúng đều là những ký ức lúc nào nghĩ tới cũng thấy xúc động lạ thường [5-7]. Điều khó có thể tưởng tượng ra chính là cuộc đời mình sẽ thế nào, nếu thiếu những món quà đến từ lao động đó. 
... 10 năm ấy, như lời kệ của Mãn Giác Thiền Sư là [8]:

Sự trục nhãn tiền quá

Lão tòng đầu thượng lai.

Lúc xưa, tóc gọi là muối tiêu, còn bây giờ thì tiêu đã tiêu tan, chỉ còn toàn muối. Quả là "già trên đầu đến rồi".

Nay lại một mùa xuân nữa về, rất đặc biệt. Trước Tết là Đại hội Đảng XIII mà rất nhiều người kỳ vọng sẽ tạo được sự đoàn kết và thúc đẩy trang sử phát triển rực rỡ mới của đất nước. Mong mỏi vào một thời kỳ đột phá kinh tế mới đưa đất nước tới thịnh vượng. Đã 12 năm kể từ khi thuật ngữ "thăng trầm và đột phá" trở nên quen thuộc với nhiều người, sau cuốn sách [9].

Sự kỳ vọng lớn lao ấy hoàn toàn có cơ sở khi lần đầu tiên tổng sản phẩm quốc nội (GDP) của đất nước trong năm 2020 quy đổi ngang giá sức mua (PPP) theo tính toán IMF đã vượt 1000 tỷ USD. Dân số Việt Nam đã chạm ngưỡng 100 triệu, một nguồn lực to lớn cho phát triển kinh tế. Dự trữ quốc gia đang ổn định và tiến tới mốc 100 tỷ USD, con số mà những người làm công việc nghiên cứu kinh tế không bao giờ tin nổi, 10 năm trước. Thị trường chứng khoán đã chạm tới ngưỡng tâm lý giá trị giao dịch tới 1 tỷ USD/ngày ngay từ tuần đầu năm 2021.

Sức vóc đất nước phần nào có được nhờ sự tự tin phục hồi sau khi đã gồng minh chống đỡ đại dịch COVID-19. Khó khăn còn đó, nhưng ý chí và mong muốn thể hiện sức sống đã và đang được tôi luyện trở nên vững mạnh và bền bỉ hơn nhiều. Lửa thử vàng, gian nan thử sức.

Trong dự cảm mùa xuân của tôi, còn có cả những hạt giống tương lai nhỏ bé, vừa mới được gieo trồng [11,12].

Bỗng chợt nhớ đến một người anh đã lớn tuổi, nhạc sỹ Dương Thụ. Mùa xuân năm ngoái, gặp lại nhau ở Buôn Ma Thuột, Đắk Lắk, sau khi xong công việc cuối năm với Trung Nguyên, anh bảo tôi: - Ông đi ăn với mình đi.

Hơi lạ, nên tôi hỏi lại: - Sao bỗng nhiên bác lại có hứng ẩm thực thế?

Anh Thụ cười, nheo nheo mắt, hiền lành: - Bao lâu rồi mới gặp nhau. Ông đừng quên mình năm nay 77 rồi. Chắc gì năm sau đã còn gặp lại nhau.

Nghe thế, thì chỉ có quăng đồ mà đi luôn chứ còn sao nữa! Không biết Tết này có dịp gặp lại nhau hay không, nhưng lời thơ trong bài ca của ông anh vẫn văng vẳng: 
Kì tiếng chim rộn hót xa vời,

Cánh hoa đào bỗng như cười, báo tin mùa xuân về...

Tìm lại mãi, mới thấy trên VNExpress có một bức ảnh chụp cùng anh Dương Thụ, từ đợt gặp lại cuối cùng với nhạc sỹ An Thuyên (hay nhất là cái lúc ấy bỗng lại có đủ cả Nguyễn Cường, Dương Trung Quốc).

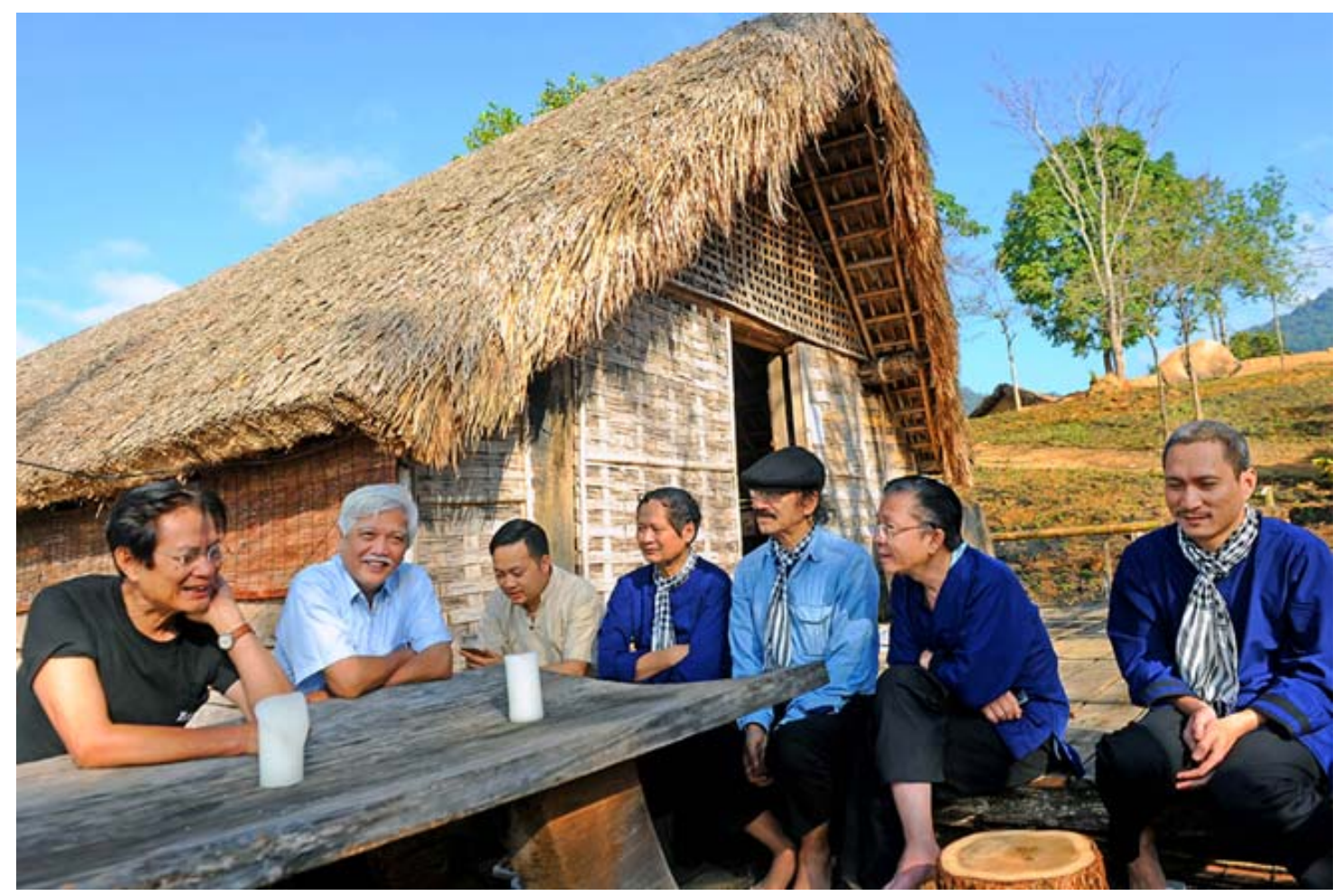

Ảnh của Nguyễn Á chụp tháng 3 năm 2015.

https://vnexpress.net/bo-anh-cuoi-nguyen-a-chup-nhac-si-an-thuyen-3243706.html

Nhạc cảm, văn tài Dương Thụ quả là tinh tế, sâu sắc. Vì thế, vần điệu và ca từ của ông rất dễ dàng đưa ta trôi giạt về miền quá khứ xa lắc xa lơ, theo cái kiểu Và Một Ngày Dài Hơn Thế Kỷ của Chingiz Aitmatov (1928-2008) đã dẫn tôi tới những thảo nguyên xa xôi của Liên Xô...

Chỉ còn khoảng 3 tuần nữa là tới Tết nguyên đán, Tân Sửu 2021.

Và chúng ta lại đón giao thừa

Phút giây lặng lẽ mong chờ, lắng nghe mùa xuân về 


\section{References}

[1] Vuong Thu Trang. (2011). The Master. (A translation of Ông Đồ by Vũ Đình Liên). Giupconhoc.com, December 25, 2011. Available from: https://osf.io/gsfce

[2] Phạm Trọng Lệ. (2018). The meaning of Tết in Việt Nam. The Firmament Literacy Journal, 10(4), 8-18. https://osf.io/gsfce

[3] Ngo Bao Chau, Vuong Quan Hoang, et al. (2020). The 80-year development of Vietnam mathematical research: Preliminary insights from the SciMath database on mathematicians, their works and their networks. arXiv preprint; arXiv:2011.09328. Available from: https://arxiv.org/abs/2011.09328

[4] Thanh-Huyen T. Nguyen, Minh-Hoang Nguyen, Manh-Toan Ho. (2021). Crossing the 100-publication milestone to celebrate the new year 2021. OSF Preprints (January 1, 2021); doi: 10.31219/osf.io/tyqj5

[5] Quan-Hoang Vuong. (2018). The (ir)rational consideration of the cost of science in transition economies. Nature Human Behaviour, 2(1), 5.

[6] Quan-Hoang Vuong. (2019). Breaking barriers in publishing demands a proactive attitude. Nature Human Behaviour, 3(10), 1034.

[7] Quan-Hoang Vuong. (2020). Reform retractions to make them more transparent. Nature, 582(7811), 149.

[8] Wikipedia. (2021). Thiền Sư Mãn Giác. Wikipedia tiếng Việt. Available from: https://vi.wikipedia.org/wiki/Mãn_Giác (accessed: Jan 16, 2021).

[9] Phạm Minh Chính, Vương Quân Hoàng. (2009). Kinh tế Việt Nam: Thăng trầm và đột phá. Nxb Chính trị quốc gia, Hà Nội.

[10] Viet-Phuong La, et al. (2020). Policy response, social media and science journalism for the sustainability of the public health system amid the COVID-19 outbreak: The Vietnam lessons. Sustainability, 12(7), 2931.

[11] Quan-Hoang Vuong. (2020). From children's literature to sustainability science, and young scientists for a more sustainable Earth. Journal of Sustainability Education, 24(3), 1-12.

[12] Quan-Hoang Vuong. (2021). The semiconducting principle of monetary and environmental values exchange. Economics and Business Letters, 10(3), in press. 